\section{ARS Tech}

Authors retain copyright

\section{Applied Research and Smart Technology}

Journal homepage: www.journals2.ums.ac.id/index.php/arstech

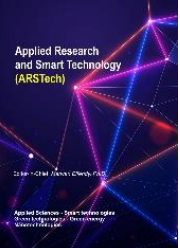

Review article

\title{
Prototype development of mecanum wheels mobile robot: A review
}

\author{
Mohd Azri Bin Abd Mutalib ${ }^{1}$, Norsinnira Zainul Azlann ${ }^{2,}$ \\ ${ }^{1}$ Machine Design Section, Machinery Technology Centre, SIRIM Berhad, No. 1A, Persiaran Zurah, Kawasan Perindustrian Rasa, \\ 44200, Hulu Selangor, Malaysia. \\ ${ }^{2}$ Department of Mechanical Engineering, Kulliyyah of Engineering, International Islamic University Malaysia, Jalan Gombak, \\ 53100. Kuala Lumpur, Malaysia.
}

${ }^{*}$ Corresponding author: sinnira@iium.edu.my

Permalink (DOI): https://doi.org/10.23917/arstech.v1i2.39

\begin{tabular}{|c|c|}
\hline ARTICLE INFO & ABSTRACT \\
\hline Article history: & This paper provides the review and prototype development of mecanum wheels \\
\hline & mobile robot (MWMR). Nowadays, there is a high market demand for a wheeled \\
\hline Received 12 June $20 \angle 0$ & machine or wheeled robot for various applications. The ability to move in any \\
\hline Kevised 00 Aug 2020 & direction without altering even a single wheel makes this type of wheel useful for \\
\hline Accepted 03 Oct 2020 & driving, especially in a narrowed or confined space. Various styles of \\
\hline Available online 30 Nov 2020 & implementing MWMR are discussed in this paper. The kinematic derivation and \\
\hline Published regularly 15 Dec 2020 & dynamic modelling are also presented. Characteristically, mecanum wheels face \\
\hline & traditional mobile application issues like jerking and slippage, contributing to \\
\hline Keywords: & low positioning accuracy and repeatability. Besides, environmental factors like \\
\hline & disturbance and uncertainty also contribute to these issues. The control strategies \\
\hline Dynamic modelling & in previous research have been reviewed and presented in this paper to reduce \\
\hline Kinematic analysis & the effect. Finally, a low-cost prototype of MWMR was developed as an \\
\hline Mecanum wheels & \\
\hline
\end{tabular}

Prototype development

\section{INTRODUCTION}

Wheeled machine-like mobile robots are becoming popular and are widely used in industries either for automated transportation or logistic purposes, such as to carry goods, parts, and even people. While dealing with an expensive and sensitive load, the mobile robot needs to be reliable and safe while providing efficient movement. A machine with its wheels can move around, leading to more efficient usage. A mobile robot that can serve more than one station in a production line can increase products' capacity and quality. 


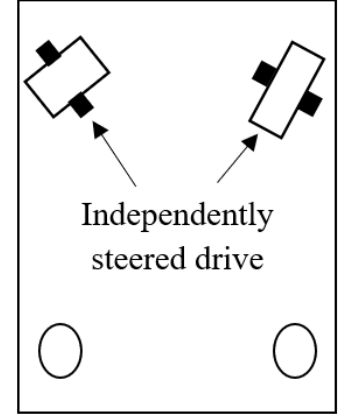

(a) Swerve drive

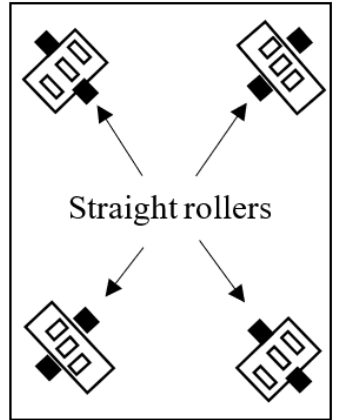

(b) Holonomic drive

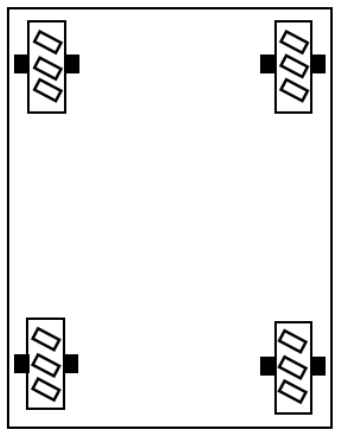

(c) Mecanum drive

Figure 1. Method approaches to implementing omnidirectional driving. $[\underline{1}]$

However, driving in a confined space where the movement is restricted is highly challenging. In this circumstance, a more effective driving strategy needs to be developed for omnidirectional driving, where the robot can move in any direction without altering the wheel orientation [2]. There are three approaches to implementing omnidirectional driving: swerving drive, holonomic drive and mecanum drive, as shown in Figure $1[1]$.

The swerve drive consists of independently steered drive modules. The concept is easy and uses simple wheels, but it is complex to build, program and control. This driving method has an advantage in manoeuvrability but is too complex to build and is less robust. The holonomic drive consists of four Omni wheels with straight rollers.
Figure 2(a) shows the photo of the Omni wheel for a holonomic drive. This type of movement is more complicated in concept and considers fairly complex wheels. It is simple to build and control but is low in traction. The mecanum drive also consists of four mecanum wheels placed at each corner of a rectangular platform, as shown in Figure 1(c). This Omni wheel has several free rollers with an oblique angle which differs from the original wheel's motion direction [3]. Figure 2(b) illustrates the photo of a mecanum wheel. The mecanum wheel has two rotations, which are the wheel rotation and roller rotation [4]. The combination of four mecanum wheels will provide a platform to move in three degrees of freedom about the normal axis of the ground from the contact point [5][6][7]. Another topology of mecanum wheel using 8, 12, 16 and 32 wheels expended from four mecanum wheels is discussed in []]. The real mecanum wheel application for the mobility of a satellite lifter trolley is also discussed in [2].

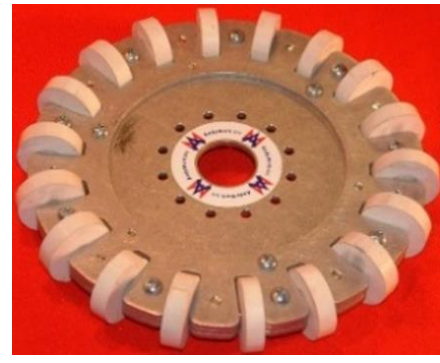

(a) Omni wheel for the holonomic drive

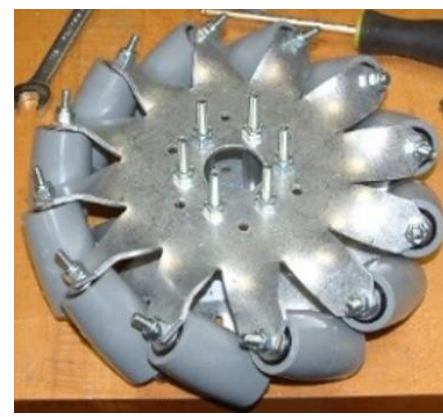

(b) Omni wheel for mecanum drive

Figure 2. Omni wheel [10].

This paper provides a review of MWMR and the prototype development used in our future study. Section 2 discusses the kinematic and dynamic derivation of the MWMR, including the possible arrangement of mecanum wheels and the possible directions. Section 3 reviews previous MWMR controllers' drawbacks to overcome the weaknesses and disturbance and uncertainties. Section 4 describes the developed MWMR prototype with essential features required as the preparation of our future study. Finally, the conclusion would be drawn in Section 5 . 


\section{MWMR KINEMATIC ANALYSIS AND DYNAMIC MODELLING}

\section{Kinematic Analysis}

Kinematics is a study of object in motion and its inter-relationship to displacement, velocity, acceleration and time [11]. For MWMR, the kinematic derivation starts from a single mecanum wheel, but the final equation depends on the mecanum wheel arrangement used. There are two types of wheel arrangements available as shown in Figure 3, where W1, W2, W3 and W4 refer to wheel 1, wheel 2, wheel 3 and wheel 4 , respectively. $\mathrm{N}$ shows the north direction of MWMR.

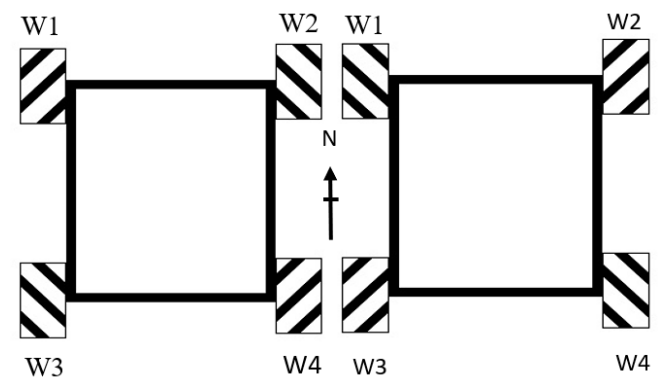

Figure 3. Possible arrangement of mecanum wheels[10]

The researchers in [1], [3], [ㄴ] $,[7],[\underline{11}]-[\underline{17}]$ [23] derived the kinematics equation using type A arrangement, while the studies in [25]-[30] used the type B arrangement. The study of both arrangements is described in [31].

Different arrangements provide different equations of forwarding kinematics. However, the combination of wheels rotation remains unchanged. Other arrangements than these two are considered wrong since not all arrangements can produce the necessary motion in the desired direction, and they require higher torque to move.

For type $A$, the kinematic derivation is as shown in Figure $4, V_{i w}$ where $(i=1,2,3,4)$ is a velocity vector corresponding to wheels revolutions with the assumption of no slippage, where $V_{i w}=R_{w} \times \omega_{i w}, R_{w}$ is the radius of the wheel, $\omega_{i w}$ is the angular velocity of the wheel and $V_{i r}(i=1,2,3,4)$ is the tangential velocity vector of the free roller contact to the floor. $L$ is the half-length of the platform, while $W$ is the half-width of the platform. The free roller angle must be at $45^{\circ}$ to ensure the least energy consumption required [32].

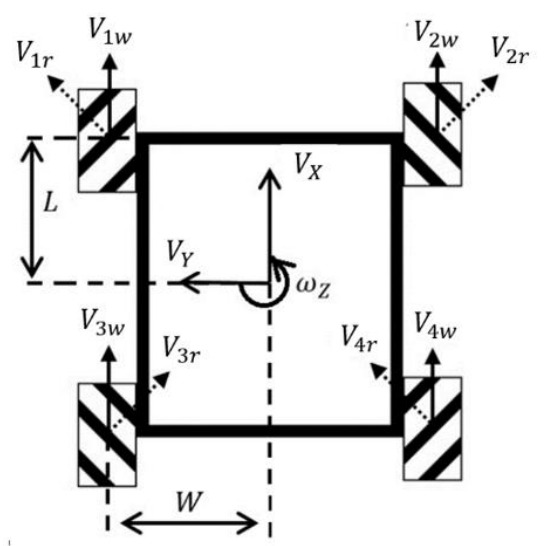

Figure 4. Model of MWMR

The linear movement of the MWMR is $V_{i X}(i=$ $1,2,3,4)$ which is derived from the wheel velocity $V_{i w}$ and $V_{\text {ir }} \mathrm{x} \cos 45^{\circ}$. Likewise, $V_{i Y}(i=1,2,3,4)$ is $V_{\text {ir }} \mathrm{x} \sin 45^{\circ}$ [5]-[Z]. The value of $\sin 45^{\circ}$ and $\cos 45^{\circ}$ used here is $1 / \sqrt{2}$. Therefore.

$\begin{array}{lll}V_{1 X}=V_{1 w}+\frac{V_{1 r}}{\sqrt{2}} \quad ; & V_{1 Y}=\frac{V_{1 r}}{\sqrt{2}} \\ V_{2 X}=V_{2 w}+\frac{V_{2 r}}{\sqrt{2}} ; & V_{2 Y}=\frac{V_{2 r}}{\sqrt{2}} \\ V_{3 X}=V_{3 w}+\frac{V_{3 r}}{\sqrt{2}} ; & V_{3 Y}=\frac{V_{3 r}}{\sqrt{2}} \\ V_{4 X}=V_{4 w}+\frac{V_{4 r}}{\sqrt{2}} & ; & V_{4 Y}=\frac{V_{4 r}}{\sqrt{2}}\end{array}$,

For rotational movement, $V_{i X}(i=1,2,3,4)$ is equal to $V_{X}$ plus the distance of the wheel centre to the platform in $X$ direction times $\omega_{z}$ and $V_{i Y}(i=1,2,3,4)$ is equal to $V_{Y}$ plus the distance of the wheel centre to the platform in $Y$ direction times $\omega_{z}$.

$V_{1 X}=V_{X}+\left(-W \omega_{z}\right) ; V_{1 Y}=V_{Y}+L \omega_{Z} \quad$,

$V_{2 X}=V_{X}+W \omega_{Z} ; V_{2 Y}=V_{Y}+L \omega_{Z}$

$V_{3 X}=V_{X}+\left(-W \omega_{z}\right) ; V_{3 Y}=V_{Y}+\left(-L \omega_{z}\right)$

$V_{4 X}=V_{X}+W \omega_{Z} ; V_{4 Y}=V_{Y}+\left(-L \omega_{Z}\right)$

Simplifying equations (1) - (8), the following equations can be obtained as

$$
\begin{aligned}
& V_{1 w}=V_{X}-V_{Y}-(L+W) \omega_{z} \\
& V_{2 w}=V_{X}+V_{Y}+(L+W) \omega_{z} \\
& V_{3 w}=V_{X}+V_{Y}-(L+W) \omega_{z} \\
& V_{4 w}=V_{X}-V_{Y}+(L+W) \omega_{z}
\end{aligned}
$$

Equations $(9-12)$ can be written in matrix form as .

$\left[\begin{array}{l}V_{1 w} \\ V_{2 w} \\ V_{3 w} \\ V_{4 w}\end{array}\right]=D\left[\begin{array}{l}V_{X} \\ V_{Y} \\ \omega_{Z}\end{array}\right]$ 
Where

$D=\left[\begin{array}{ccc}1 & -1 & -(L+W) \\ 1 & 1 & (L+W) \\ 1 & 1 & -(L+W) \\ 1 & -1 & (L+W)\end{array}\right]$

Since $V_{i w}=R_{w} \times \omega_{i w}$ and $R_{w}$ is identical for all the four wheels;

$\left[\begin{array}{l}V_{1 w} \\ V_{2 w} \\ V_{3 w} \\ V_{4 w}\end{array}\right]=\left[\begin{array}{ll}R_{W} & \omega_{1 W} \\ R_{W} & \omega_{2 W} \\ R_{W} & \omega_{3 W} \\ R_{W} & \omega_{4 W}\end{array}\right]$

To solve this equation, matrix $D$ in equation (14) has to be transformed using the pseudo-inverse method, where

$D^{+}=\left(D^{T} \cdot D\right)^{-1} D^{T}$

$=\frac{1}{4}\left[\begin{array}{cccc}1 & 1 & 1 & 1 \\ -1 & 1 & 1 & -1 \\ \frac{1}{-(L+W)} & \frac{1}{(L+W)} & \frac{1}{-(L+W)} & \frac{1}{(L+W)}\end{array}\right]$

Rearranging equations (13 - 15), the forward kinematic equation for type $A$ arrangement can be obtained as;

$\left[\begin{array}{l}V_{X} \\ V_{Y} \\ \omega_{Z}\end{array}\right]=\frac{R_{W}}{4}\left[\begin{array}{cccc}1 & 1 & 1 & 1 \\ -1 & 1 & 1 & -1 \\ \frac{1}{-(L+W)} & \frac{1}{(L+W)} & \frac{1}{-(L+W)} & \frac{1}{(L+W)}\end{array}\right]\left[\begin{array}{c}\omega_{1 W} \\ \omega_{2 W} \\ \omega_{3 W} \\ \omega_{4 W}\end{array}\right]$

On the other hand, for the kinematic derivation using type B arrangement, the forward kinematic equation is;

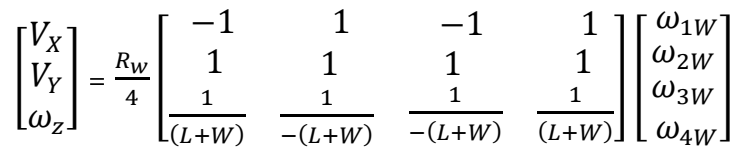

Table 1. Combination of wheels rotation in producing MWMR motions.

\begin{tabular}{lcccc}
\hline Directions & W1 & W2 & W3 & W4 \\
\hline North & + & + & + & + \\
South & - & - & - & - \\
East & + & - & - & + \\
West & - & + & + & - \\
North East & + & 0 & 0 & + \\
North West & 0 & + & + & 0 \\
South East & - & 0 & 0 & - \\
South West & 0 & - & - & 0 \\
Clockwise & + & - & + & - \\
Counter & - & + & - & + \\
clockwise & & & & \\
\hline
\end{tabular}

The difference between Eq. (17) and Eq. (18) is in the negative sign (-). However, this difference does not affect the combination of wheels rotation in producing MWMR motion direction. For the arrangement of the mecanum wheel, as shown in Figure 3, the direction of the movement concerning the wheel's rotation can be summarized in Table 1 where ' + ' refers to clockwise rotation and '-' is counter clockwise. The number ' 0 ' means that the wheel remains stopped, and only the free rollers are rotating [14] [23] [28].

\section{Dynamic Modelling}

Kinematic analysis is a calculation to find the platform distance moved on $\mathrm{X}$, Y or theta directions while dynamic modelling calculates this movement. Therefore, the dynamic modelling will involve mass, friction to the floor, and torque required to move the MWMR. This study is essential since the movement of MWMR is needed to be smooth and free from jerks, especially if the MWMR has to carry a heavy load or need to move fast.

Most MWMR studies are conducted with laboratory prototypes. Since the size, load, speed, and precision target are small, not much reference was derived on dynamic modelling. Total kinetic energy, $K$ is given by equation (19).

$K=\frac{1}{2} m\left(V_{X}^{2}+V_{Y}^{2}\right)+\frac{1}{2} J_{Z} \omega_{Z}^{2}+\frac{1}{2} J_{W}\left(V_{1 w}{ }^{2}+V_{2 w}{ }^{2}+\right.$
$\left.V_{3 w}{ }^{2}+V_{4 w}{ }^{2}\right)$

where $m$ is the total mass of MWMR, $J_{Z}$ is the MWMR moment inertia around $Z$-axis and $J_{W}$ is the wheel moment inertia around the centre revolution. The loss of energy, $E$ is expressed in equation (20), where $\mu$ is the wheel friction coefficients.

$$
E=\frac{1}{2} \mu\left(V_{1 w}{ }^{2}+V_{2 w}{ }^{2}+V_{3 w}{ }^{2}+V_{4 w}{ }^{2}\right),
$$

By substituting the kinematic equation into equation (19) and utilizing the Lagrange equation; it yields

$$
\begin{aligned}
\tau= & M \ddot{\theta}+\mu \quad \dot{\theta} \\
& \text { where } \\
\boldsymbol{\theta}= & {\left[\begin{array}{l}
\theta_{1} \\
\theta_{2} \\
\theta_{3} \\
\theta_{4}
\end{array}\right] \quad ; \boldsymbol{\tau}=\left[\begin{array}{l}
\tau_{1} \\
\tau_{2} \\
\tau_{3} \\
\tau_{4}
\end{array}\right] } \\
\boldsymbol{M} & =\left[\begin{array}{cccc}
A+B+J_{W} & -B & B & A-B \\
-B & A+B+J_{W} & A-B & B \\
B & A-B & A+B+J_{W} & -B \\
A-B & B & -B & A+B+J_{W}
\end{array}\right] \\
A=\frac{m R^{2}}{8} & B=\frac{J_{Z} R^{2}}{16(L+W)^{2}}
\end{aligned}
$$




\section{MWMR CONTROL SYSTEMS}

Although the mecanum wheel has an advantage in manoeuvring, it also comes with weakness inefficiency. Slippage issue is the foremost concern while developing this type of wheel which makes it rarely applied as unmanned mobile robot [34-35]. The $45^{\circ}$ free rollers are the cause of the slippage. Besides that, each mecanum wheel must be driven with separate motors, and the motors need to be synchronous in rotation [36]. A minor asynchronous rotation will affect the movement of the platform. Besides, the sensor used in the MWMR also influences the gap and creates unwanted movement. Several types of research have been conducted to improve the MWMR, as shown in Table 2.

Table 2. Previous work on improving MWMR.

\begin{tabular}{|c|c|c|c|c|c|c|}
\hline No & Author & Controller & $\begin{array}{l}\text { Controlled } \\
\text { Parameter }\end{array}$ & $\begin{array}{l}\text { With } \\
\text { Hardware? }\end{array}$ & Problem Solved & Remarks \\
\hline 1 & $\begin{array}{l}\text { Shimada et al., } \\
2005[\underline{4}]\end{array}$ & PD Controller & $\begin{array}{l}\text { Position/ } \\
\text { Velocity }\end{array}$ & Yes & Slipped & $\begin{array}{l}\text { To replace a camera as an external } \\
\text { sensor with distance sensor for more } \\
\text { convenience. }\end{array}$ \\
\hline 2 & $\begin{array}{l}\text { Christopher M. } \\
\text { Kumile, } 2005 \\
{[33]}\end{array}$ & $\begin{array}{l}\text { Fuzzy Logic } \\
\text { Controller }\end{array}$ & $\begin{array}{l}\text { Position/ } \\
\text { Velocity }\end{array}$ & Yes & $\begin{array}{l}\text { The noise of the } \\
\text { sensor and slipped }\end{array}$ & $\begin{array}{l}\text { Usage of hardware looks complex. } \\
\text { Results are not showing in a graph; not } \\
\text { clear between before and after } \\
\text { controlled parameter. }\end{array}$ \\
\hline 3 & $\begin{array}{l}\text { Pakpoom } \\
\text { Viboonhaicheep, } \\
2005[16\end{array}$ & $\begin{array}{l}\text { Position } \\
\text { Rectification }\end{array}$ & $\begin{array}{l}\text { Position/ } \\
\text { Velocity }\end{array}$ & No & Slipped & $\begin{array}{l}\text { Simulation only. Interesting to see the } \\
\text { slipped was entertained as a } \\
\text { disturbance. We were suggested to } \\
\text { pursue with experiment. }\end{array}$ \\
\hline 4 & $\begin{array}{l}\text { Lin-Chang Lin, } \\
2008[25]\end{array}$ & $\begin{array}{l}\text { Adaptive } \\
\text { controller }\end{array}$ & $\begin{array}{l}\text { Torque/ } \\
\text { force }\end{array}$ & No & Mass and friction & $\begin{array}{l}\text { A slipped issue which is the foremost } \\
\text { concern in designing MWMR, was } \\
\text { considered at all. }\end{array}$ \\
\hline 5 & $\begin{array}{l}\text { Kyung-Lyong } \\
\text { Han, } 2009[37]\end{array}$ & Fuzzy- PID & $\begin{array}{l}\text { Platform } \\
\text { Velocity }\end{array}$ & Yes & $\begin{array}{l}\text { The bad response } \\
\text { of previous } \\
\text { MWMR. }\end{array}$ & $\begin{array}{l}\text { Real-time calculation but considered } \\
\text { either disturbance or uncertainty. }\end{array}$ \\
\hline 6 & $\begin{array}{l}\text { Jungje Park, } 2010 \\
{[1]}\end{array}$ & Fuzzy Logic & $\begin{array}{l}\text { Angular } \\
\text { velocity }\end{array}$ & Yes & Slipped & $\begin{array}{l}\text { The slipped error was only considered } \\
\text { from variance reading of each encoder } \\
\text { and suggested to use distance sensor as } \\
\text { the second reference for better result. }\end{array}$ \\
\hline 7 & $\begin{array}{l}\text { Ching - Chih } \\
\text { Tsai, } 2010[14]\end{array}$ & $\begin{array}{l}\text { Non-singular } \\
\text { terminal SMC, } \\
\text { Fuzzy wavelet } \\
\text { networks }\end{array}$ & $\begin{array}{l}\text { Position/ } \\
\text { Velocity }\end{array}$ & No & Slipped & $\begin{array}{l}\text { Consider a non-linear system with } \\
\text { modelled friction but not include the } \\
\text { load change }\end{array}$ \\
\hline 8 & $\begin{array}{l}\text { Ching - Chih } \\
\text { Tsai,2011 [12] }\end{array}$ & Dead reckoning & $\begin{array}{l}\text { Angular } \\
\text { velocity/ } \\
\text { position }\end{array}$ & Yes & $\begin{array}{l}\text { Trajectory } \\
\text { accuracy }\end{array}$ & $\begin{array}{l}\text { Focused on accuracy only, not the } \\
\text { velocity of the robot. }\end{array}$ \\
\hline 9 & $\begin{array}{l}\text { Filip Toth, } 2013 \\
{[38]}\end{array}$ & $\begin{array}{l}\text { Accuracy-based } \\
\text { classifier } \\
\text { systems (XCS) }\end{array}$ & Velocity & Yes & $\begin{array}{l}\text { To move MWMR } \\
\text { along wall and } \\
\text { obstacles } \\
\text { avoidance }\end{array}$ & $\begin{array}{l}\text { Controller design has less effect on } \\
\text { friction. }\end{array}$ \\
\hline 10 & $\begin{array}{l}\text { Filip Toth, } 2013 \\
{[\underline{39]}}\end{array}$ & $\begin{array}{l}\text { Proportional Sum } \\
\text { Derivative (PSD), } \\
\text { PS regulator }\end{array}$ & $\begin{array}{l}\text { Position/ } \\
\text { Velocity }\end{array}$ & Yes & $\begin{array}{l}\text { Jerking while } \\
\text { accelerating and } \\
\text { decelerating }\end{array}$ & $\begin{array}{l}\text { Single motor control. For better } \\
\text { outcome, control of } 4 \text { motors is a must } \\
\text { since they will produce one direction. }\end{array}$ \\
\hline 11 & Ren C, 2015 [Z] & Adaptive control & $\begin{array}{l}\text { Force, } \\
\text { slippage, } \\
\text { center } \\
\text { gravity } \\
\text { displacement }\end{array}$ & Yes & $\begin{array}{l}\text { Slippage with } \\
\text { simultaneous } \\
\text { operation of } \\
\text { mobile platform } \\
\text { and robot } \\
\text { manipulator. }\end{array}$ & $\begin{array}{l}\text { Problem is solved due to the pose arm } \\
\text { only by adjusting the kinematic model } \\
\text { and suggested to consider uncertainty } \\
\text { and disturbance. }\end{array}$ \\
\hline 12 & $\begin{array}{l}\text { Qi-Ye Zhang, } \\
2015 \text { [13] }\end{array}$ & $\begin{array}{l}\text { TSK fuzzy, } \\
\text { Adaptive SMC }\end{array}$ & $\begin{array}{l}\text { Position/ } \\
\text { Velocity }\end{array}$ & No & Slipped. & $\begin{array}{l}\text { Strongly suggested continuing with } \\
\text { experiment to verify the robustness of } \\
\text { the proposed controller. }\end{array}$ \\
\hline
\end{tabular}


AFM Fuad, 2016

[18]

Model Predictive

Control

Angular

velocity

14

Fahmizal, 2016

[22]

Fuzzy logic

Position/

Yes

Velocity

15

Veer Alakshendra, Adaptive SMC 2016 [28]

law.

Position/

Velocity

Panagiotis Vlantis, Adaptive control 2016 [29]

17

Ching-Chih Tsai,
2016 [15]

William A. Blyth, PI Controller 2016 [30]

Ching-Chih Tsai, 2016[17]

Shahrooz Shahin, 2017 [20]

21

Rasoul Sadeghian, 2017 [40]

22 Zhang Lieping, 2017 [21]

Intelligent SMC,

Fuzzy wavelet neural networks

Angular

velocity/

position

Position/

Velocity

Position/

Velocity

Yes

Yes

Yes

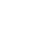

accuracy
Slipped and
gravity

\section{Trajectories} accuracy

\section{Desynchronizatio} $\mathrm{n}$ of the robot's motor from vibration effect

Noise of sensor

Fuzzy Logic,

Digital I/O Yes

Kalman Filter

Dual PID

Motor and Yes

Control Systems

platform

velocity
23 Rongyan Wen,
2017 [27]

24

\section{Neural-Fuzzy PID}

Position/

Velocity

$\begin{array}{ll}\text { Adaptive non- } & \text { Position/ } \\ \text { singular terminal } & \text { Velocity } \\ \text { sliding mode } & \\ \text { formation control. } & \end{array}$

\section{High energy}

consumption and

mismatch

between the

gimbal and

movement of the

chassis

Delay in

orthogonal

turning

Generate general

equation for 3

different types of

MWMR
Simulation on a single wheel is

suggested to pursue with four mecanum wheels to verify the platform movement.

The IMU provided good navigation to the robot and reduced the trajectory's deviation but required an excellent sensor system.

The deviation between trajectories reduced-involved in complex calculation.

Focused on positioning accuracy; did not include the velocity of the robot.

The calculations are very complex, expected to be challenging to be embedded to a microcontroller.

The controller is designed for specific use (pipeline inspection). Cannot be used for a different type of pipe or another MWMR system.

The calculations are very complex, expected difficult to be embedded to a microcontroller.

Slipped was not considered, and the rollers were assuming as a rigid body.

Improved the movement of MWMR with reducing the noise of the sensor.

Mass and floor friction must be constant. Otherwise, will affect the controller parameter.

Result of simulation and experiment are not stated clearly.

Simulation only.
Most of them solved the slippage issue by controlling the rotation of the motor. Jungje Park, 2010 [1] used an encoder attached with the motor to count the motor's rotation. Then, the readings are compared to all four wheels, and a fuzzy logic controller was applied to verify which encoder reading will be the reference.

Instead of comparing that reading, Akira Shamada, 2005 [4] implemented the camera as an external sensor to achieve the required accuracy. However, this method involves a complex image processing study to measure distance. Christopher M. Kumile, 2005 [33], Veer Alakshendra, 2016 [28] and Rasoul Sadeghian, 2017 [40] applied external sensor to measure the distance and suggested controllers reduce the sensor noise and overcome the delay. Fahmizal, 2016 [22] utilized the IMU sensor to determine the direction where the robot is heading to and fuzzy logic control to moderate the slippage issue. 
To improve the movement of MWMR, the quality of each motor rotation also needs to be deliberated. Filip Toth, 2013 [32] and AFM Fuad, 2016 [18] discussed the single motor controlled with improving motor velocity profile. The mobile robot was also designed to carry loads to be a transporter for materials and humans. Lin-Chang Lin, 2008 [25] discussed the eccentricity influence and overcomes the issue by implementing an adaptive controller. However, the slip issue, which is the foremost concern while using mecanum wheel, is ignored.

MWMR manoeuvring is highly challenging to control MWMR to follow the desired trajectory during orthogonal turning. Reducing the turning speed or putting some delay for orthogonal turning can generally solve the problem. Rongyan Wen, 2017 [27] suggested neuro fuzzyPID controller that can speed up the turning and decrease the delay. Likewise, position accuracy has been pointed out by Pakpoom Viboonhaicheep, 2005 [16], and the researcher team suggested a controller called position rectification control. Panagiotis Vlantis, 2016 [22] investigated the fault of up to two units of mecanum wheel. The platform can still reach an accepted accuracy. Unfortunately, both of them only work on position accuracy, which omits the velocity.

The real-time or online calculation is the best methods to achieve high accuracy and overcome slippage. KyungLyong Han, 2009 [37], Ching - Chih Tsai, 2010 [14] and Ching - Chih Tsai,2011 [12] are among the researchers who have implemented this method with their selected controller as listed in Table 2. This method can be implemented either with the kinematic or dynamic model with the implementer's appropriate sensors. Instead of doing online, Qi-Ye Zhang, 2015 [13], Ching-Chih Tsai, 2016 [17] and Ching-Chih Tsai, 2016 [30] are the successors who showed their designed controller in simulation. The results show that a slip issue could be solved, but the proposed methods involve complex calculation. It is expected that difficulty will occur while transferring the algorithm into a microcontroller. Their study can be extended with experiments to prove that their designed controller is robust to handle disturbance and uncertainty.

Besides, the accuracy of MWMR movement also dropped due to vibration effect from the coupling of the motor shaft and robot hub. Shahrooz Shahin, 2017 [20] had used a PID controller to overcome the impact and verify the result by comparing the distance travel by MWMR with their encoder reading. Rather than researching MWMR movement, Zhang Lieping, 2017 [21] focused on the high energy consumption in MWMR movement with a proposed dual PID controller system. The mismatch between gimbal and chassis has been solved and reduced energy consumption.
MWMR has also been casual in avoiding obstacles by itself. Filip Toth, 2013 [38] recommended using accuracybased classifier systems (XCS) to realize obstacle avoidance in MWMR. MWMR was also explored to work for specific applications. For example, William A. Blyth, 2016 [30] introduced MWMR to move along a pipe surface for pipe inspection purpose. The low performance of MWMR, including gravity effect, was improved by using PI controller. Besides, Ren C, 2015 [Z] replaced the robot manipulator wheels with mecanum wheels. An adaptive controller was applied to overcome the usual slippage and divert the centre of centre gravity due to different post arm. Since the usage of mecanum wheels has expanded, Hsiao Lang Wu, 2017 [23] worked on generalizing the MWMR equation. Three different modes of mecanum wheels were simulated and an adaptive non-singular terminal sliding mode formation control was applied to improve the movement.

\section{DEVELOPMENT OF MWMR PROTOTYPE IN INTERNATIONAL ISLAMIC UNIVERSITY MALAYSIA}

Based on the previous section review, a basic prototype was developed to continue exploring the control of MWMR to overcome slippage. All required components are listed in Table 3. The development includes several processes such as modelling, machining, and fitting before completing the assembly. Mild steal plate with $3 \mathrm{~mm}$ thickness was used as a base structure, as shown in Figure 5, while Figure 6 illustrates the complete assembly of the MWMR prototype.

Table 3. MWMR Prototype Equipment.

\begin{tabular}{cllc}
\hline No & Item & \multicolumn{1}{c}{ Model Number } & Quantity \\
\hline 1 & Mecanum wheel & CYT3626 & 4 \\
2 & $\begin{array}{l}\text { Dc motor with } \\
\text { encoder }\end{array}$ & SPG30E-60K & 4 \\
3 & Motor driver & MD10C & \\
4 & Motor holder & SD-SS-10 & 4 \\
5 & Arduino mega & 2560 Rev 3 & 4 \\
6 & Distance sensor & SN-GP2D120XJ00F & 3 \\
7 & Battery & LIP-11,1500 & 1 \\
8 & Charger & LIP-CR-B6AC & 1 \\
9 & Voltage & LM78051C & 1 \\
& regulator & & 1 \\
\hline 10 & Breadboard & BD-BB-0617 & \\
\hline
\end{tabular}




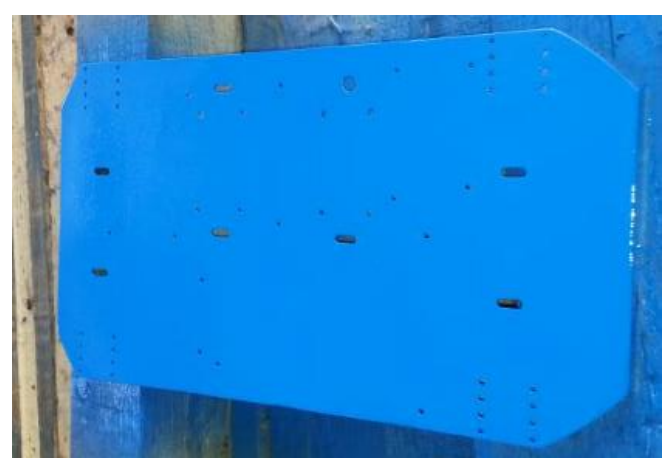

Figure 5. Base structure of MWMR prototype.

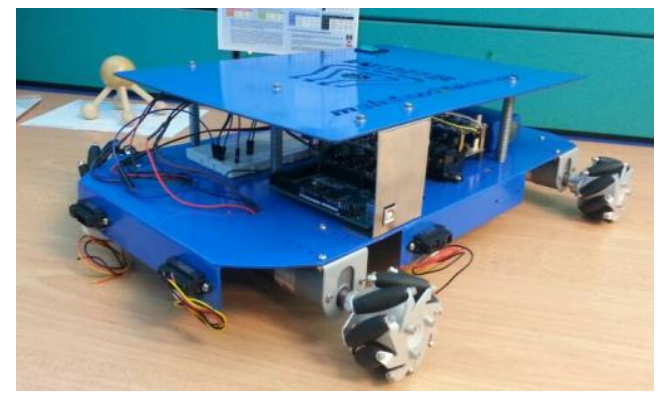

Figure 6. MWMR prototype complete assembly

Three units of distance sensors have been attached to the MWMR prototype; two units at the front site and one unit at the left side, as shown in Figure 6. Both sensor readings at the front site would be compared to determine the straightness of the MWMR. The slight divergence between those reading indicates that the MWMR's movement is not straight, while the sensor at the left side will define the sideways movement.

An individual DC motor will drive the MWMR. Since the motor rotation needs to be measured, all four motors are embedded with an encoder. For more convenience, the MWMR is powered by a battery. The Arduino Mega microcontroller has been selected since it has four analogue outputs in the Arduino family and was used by $[\underline{20]},[28],[\underline{40]}$ and [1ㅣ]. The price is also reasonable compared to others.

At this stage of the study, the MWMR prototype is ready to be used in the experiment of our future study to overcome the slippage issue while considering the uncertainties and disturbances. In order to reduce the controller's complexity, it is planned that the slippage is modelled, as discussed in [Z]. The controller will be designed with real-time calculation to maximize its robustness. The controller also needs to be designed as simple as possible to avoid any difficulties while programming an algorithm into the microcontroller.

\section{CONCLUSION}

This paper provides a review of MWMR and its prototype development for our future study. The history of mecanum wheel development has been discussed. Two different wheels arrangements have also been described, and the combination of mecanum wheels rotation have been weighed up in producing MWMR movement. The difference between these arrangements resulted in the dissimilar general kinematic equation. A dynamic study is required if the quality response of MWMR is compulsory. The review shows that the position accuracy, velocity control, slippages, and environmental influences like disturbances and uncertainties are the main issues affecting MWMR performance. The previous controllers' issues include the complexity of an algorithm embedded into the microcontroller and the offline parameter control which needs to be improved. Therefore, our future study will focus on solving these issues by developing a new controller with online parameter control and minimum algorithm complexity suitable to Arduino Mega's capacity. To pursue this research, an MWMR prototype was developed with the required features for our future study.

\section{CONFLICTS OF INTEREST}

The authors declare no conflicts of interest.

\section{ACKNOWLEDGEMENT}

The authors would like to thank the International Islamic University Malaysia for supporting this research.

\section{REFERENCES}

[1] J. Park, S. Kim, J. Kim and S. Kim, "Driving control of mobile robot with mecanum wheel using fuzzy inference system", International Conference on Control, Automation and Systems (CCAS), Gyeonggido, pp.2519-2523, 2010. https://doi.org/10.1109/ICCAS.2010.5670241.

[2] Y. Uchida, T. Saito, and T. Hatakeyama, "Development of a multi-purpose module system using mecanum wheel module", International Journal of Applied Electromagnetics and Mechanics, vol.59, no.3, pp.967-975, 2019. https://doi.org/10.3233/JAE-171096.

[3] Y. Jia, X. Song and S.S. Xu, "Modeling and motion analysis of four-mecanum wheel omni-directional mobile platform", International Automatic Control Conference (CACS), Nantou, pp. 328-333, 2013. https://doi.org/10.1109/CACS.2013.6734155. 
[4] A. Shimada, S. Yajima, P. Viboonchaicheep and K. Samura, "Mecanum-wheel vehicle systems based on position corrective control", The 31st Annual Conference of IEEE Industrial Electronics Society (IECON), Raleigh, NC, 2005, pp. 2077-2082, 2005.

https://doi.org/10.1109/IECON.2005.1569224

[5] J.-B. Song and K.-S. Byun, "Design and control of a four-wheeled omnidirectional mobile robot with steerable omnidirectional wheels", Journal of Robotic Systems, vol. 21, no. 4, pp.193-208, 2004. https://doi.org/10.1002/rob.20002.

[6] P. Muir and C. Neuman, "Kinematic modeling for feedback control of an omnidirectional wheeled mobile robot", Proceedings. 1987 IEEE International Conference on Robotics and Automation, Raleigh, NC, USA, 1987, pp.1772-1778, 1987.

https://doi.org/10.1109/ROBOT.1987.1087767

[7] Y.-S. T. Ren and C.Luo, "Online adaptive control for minimizing slippage error while mobile platform and manipulator operate simultaneously for robotics mobile manipulation", The 41st Annual Conference of the IEEE Industrial Electronics Society, pp. 26792684, 2015.

https://doi.org/10.1109/IECON.2015.7392506.

[8] Y. Li, S. Dai, L. Zhao, X. Yan, and Y. Shi, "Topological design methods for mecanum wheel configurations of an omnidirectional mobile robot", Symmetry, vol. 11, no. 10, pp.1268. 2019. https://doi.org/10.3390/sym11101268.

[9] M.A.A. Mutalib, N.Z. Azlan, and I.A.B. Mahmood, "Modelling of mobility mechanism for motorized adjustable vertical platform (MAVeP)", International Conference on Automatic Control and Intelligent Systems (I2CACIS), Shah Alam, pp. 3946, 2018.

https://doi.org/10.1109/I2CACIS.2018.8603699.

[10] Simbotics Team 1114, "Omnidirectional Drive," 2018.

[11] Z. Lieping, H. Chaoning, and C. Peng, "Design of limited power omni-directional vehicle based on chassis follow," International Conference on Smart City and Systems Engineering (ICSCSE), Changsha, pp.10-13, 2017, https://doi.org/10.1109/ICSCSE.2017.10.
[12] C. Tsai, F. Tai and Y. Lee, "Motion controller design and embedded realization for mecanum wheeled omnidirectional robots", 2011 th World Congress on Intelligent Control and Automation, Taipei, pp.546551, 2011.

https://doi.org/10.1109/WCICA.2011.5970573.

[13] Q. Zhang, D. Li, W. Pei, and Y. Jia, "A TSK fuzzy model and adaptive sliding-mode controller design for four-Mecanum-wheel omni-directional mobile free-bases", Chinese Automation Congress (CAC), Wuhan, pp.1862-1867, 2015. https://doi.org/10.1109/CAC.2015.7382807.

[14] C. Tsai, and H. Wu, "Non-singular terminal sliding control using fuzzy wavelet networks for mecanum wheeled omni-directional vehicles", International Conference on Fuzzy Systems, Barcelona. pp.1-6, 2010.

https://doi.org/10.1109/FUZZY.2010.5584223.

[15] C. Tsai, H. Wu and F. Tai, "Intelligent slidingmode formation control for uncertain networked heterogeneous mecanum-wheeled omni directional platforms," 2016 IEEE International Conference on Systems, Man, and Cybernetics (SMC), Budapest, 2016, pp. 539-544, https://doi.org/10.1109/SMC.2016.7844295.

[16] P. Viboonchaicheep, A. Shimada and Y. Kosaka, "Position rectification control for mecanum wheeled omni-directional vehicles", IECON'03. IECON'03 29th Annual Conference of the IEEE Industrial Electronics Society (IEEE Cat. No.03CH37468), Roanoke, VA, USA, 2003, pp. 854-859 vol.1, https://doi.org/10.1109/IECON.2003.1280094.

[17] C. Tsai, H. Wu, F. Tai and Y. Chen, "Adaptive backstepping decentralized formation control using fuzzy wavelet neural networks for uncertain mecanum-wheeled omnidirectional multi-vehicles," 2016 IEEE International Conference on Industrial Technology (ICIT), Taipei, pp. 1446-1451, 2016. https://doi.org/10.1109/ICIT.2016.7474971.

[18] AFM Fuad, I.A. Mahmood, S. Ahmad, N.M.H. Norsahperi, S.F. Toha, R. Akmeliawati and F.J. Darsivan, "Modeling and simulation for heavy-duty mecanum wheel platform using model predictive control", IOP Conference Series: Materials Science and Engineering, vol. 184, p. 012050. 2017. https://doi.org/10.1088/1742-6596/755/1/011001. 
[19] K. Han, H. Kim and J. S. Lee, "The sources of position errors of omni-directional mobile robot with mecanum wheel", 2010 IEEE International Conference on Systems, Man and Cybernetics, Istanbul, pp.581-586, 2010. https://doi.org/2010.1109/ICSMC.202010.56420 09.

[20] S. Shahin, R. Sadeghian, P. Sedigh and M.T. Masouleh, "Simulation, control and construction of a four mecanum-wheeled robot," 2017 IEEE 4th International Conference on Knowledge-Based Engineering and Innovation (KBEI), Tehran, pp. 0315-0319, 2017.

\section{https://doi.org/10.1109/KBEI.2017.8324993.}

[21] Z. Lieping, H. Chaoning and C. Peng, "Design of limited power omni-directional vehicle based on chassis follow", The International Conference on Smart City and Systems Engineering (ICSCSE), Changsha, pp.10-13, 2017.

https://doi.org/10.1109/ICSCSE.2017.10.

[22] Fahmizal and C. Kuo, "Trajectory and heading tracking of a mecanum wheeled robot using fuzzy logic control", International Conference on Instrumentation, Control and Automation (ICA), Bandung, pp.54-59, 2016. https://doi.org/2010.1109/ICA.2016.7811475.

[23] H. Wu, C. Tsai and F. Tai, "Adaptive nonsingular terminal sliding-mode formation control using ORFWNN for uncertain networked heterogeneous mecanum-wheeled omni directional robots", The IEEE International Conference on Systems, Man, and Cybernetics (SMC), Banff, AB, pp. 3317-3322, 2017.

https://doi.org/10.1109/SMC.2017.8123141.

[24] L. Xie, W. Herberger, W. Xu and KA Stol, "Experimental validation of energy consumption model for the four-wheeled omnidirectional mecanum robots for energy-optimal motion control", IEEE 14th International Workshop on Advanced Motion Control (AMC), Auckland, pp. 565-572, 2016.

https://doi.org/10.1109/AMC.2016.7496410.

[25] L.-C. Lin and H.-Y. Shih, "Modeling and adaptive control of an omni-mecanum-wheeled robot", Intelligent Control Automation, vol. 4, no. 2, pp. 166-179, 2013.

https://doi.org/10.4236/ica.2013.42021.
[26] P. Chotikunnan, T. Matsuura, N. Thongpance, M. Sangworasil, T. Pluemchan, P. Wannarat, and A. Teerasoradech, "The design and construction of surrounding control system for the rehabilitative walker using mecanum wheel", 10th Biomedical Engineering International Conference (BMEiCON), Hokkaido, pp.1-4, 2017. https://doi.org/10.1109/BMEiCON.2017.822916 $\underline{6}$.

[27] R. Wen and M. Tong, "Mecanum wheels with Astar algorithm and fuzzy PID algorithm based on genetic algorithm", International Conference on Robotics and Automation Sciences (ICRAS), Hong Kong, pp. 114118, 2017.

https://doi.org/10.1109/ICRAS.2017.8071927.

[28] V. Alakshendra, and S.S. Chiddarwar, "A robust adaptive control of mecanum wheel mobile robot: Simulation and experimental validation," IEEE/RSJ International Conference on Intelligent Robots and Systems (IROS), Daejeon, pp. 5606-5611, 2016. https://doi.org/10.1109/IROS.2016.7759824.

[29] P. Vlantis, C.P. Bechlioulis, G. Karras, G. Fourlas, and K. J. Kyriakopoulos, "Fault tolerant control for omni-directional mobile platforms with 4 mecanum wheels", IEEE International Conference on Robotics and Automation (ICRA), Stockholm, pp. 23952400, 2016.

https://doi.org/10.1109/ICRA.2016.7487389.

[30] W.A. Blyth, D.R.W. Barr, and F. Rodriguez y Baena, "A reduced actuation mecanum wheel platform for pipe inspection," IEEE International Conference on Advanced Intelligent Mechatronics (AIM), Banff pp. 419-424, 2016. https://doi.org/ 10.1109/AIM.2016.7576803.

[31] C. He, D. Wu, K. Chen, F. Liu, and N. Fan, "Analysis of the mecanum wheel arrangement of an omnidirectional vehicle", Proceedings of the Instituion of Mechanical Engineers, Part C: Journal of Mechanical Engineering Science, vol. 233, no. 15, pp. 5329-5340, 2019. https://doi.org/10.1177/0954406219843568.

[32] L. Zhang, J. Kim, and J. Sun, "Energy modeling and experimental validation of four-wheel mecanum mobile robots for energy-optimal motion control", Symmetry, vol. 11, no. 11, pp.1372, 2019, https://doi.org/10.3390/sym11111372. 
[33] C.M. Kumile, and NS. Tlale, "Intelligent distributed fuzzy logic control system (IDFLCS) of a mecanum wheeled autonomous guided vehicle", IEEE IEEE International Conference Mechatronics and Automation, 2005, Niagara Falls, Ontario, pp. 131-137, 2005.

https://doi.org/10.1109/ICMA.2005.1626535.

[34] Y. Li, S. Dai, Y. Shi, L. Zhao, and M. Ding, "Navigation simulation of a mecanum wheel mobile robot based on an improved $A^{*}$ Algorithm in unity 3D," Sensors, vol. 19, pp. 2976, 2019. https://doi.org/10.3390/s19132976.

[35] I. Oh, G. Kwon, and H. Yang, "A study of position estimation considering wheel slip of mecanum wheeled mobile robot", Journal of the Korea Institute of Military Science and Technology, 22, no. 3, pp.401407, 2019.

https://doi.org/10.9766/KIMST.2019.22.3.401.

[36] R. Bai, "Workbench control system design based on mecanum wheel," IOP Conference Series Materials Science and Engineering, vol. 688, 022062, 2019, https://doi.org/10.1088/1757899X/688/2/022062.

[37] K. Han, O. Choi, J. Kim, H. Kim, and J. S. Lee, "Design and control of mobile robot with mecanum wheel," ICCAS-SICE, Fukuoka, pp. 2932-2937, 2009.
[38] F. Tóth, K. Rebrová, G. Zatko, P. Krasňanský, and B. Roha'l-Ilkiv, "Mobile robot control using XCS", International Conference on Process Control (PC), Strbske Pleso, pp. 504-509, 2013. https://doi.org/10.1109/PC.2013.6581461.

[39] F. Tóth, P. Krasňanský, M. Gulan, and B. Rohal'Ilkiv, "Control systems in omni-directional robotic vehicle with mecanum wheels", International Conference on Process Control (PC), Strbske Pleso, pp. 516-521, 2013.

https://doi.org/10.1109/PC.2013.6581463.

[40] R. Sadeghian, P. Azizinezhad, P. Sedigh, S. Shahin and M.T. Masouleh, "Control of a four-mecanum wheeled robot with a soft-robotic glove", IEEE 4th International Conference on Knowledge-Based Engineering and Innovation (KBEI), Tehran, pp. 310-314, 2017.

https://doi.org/10.1109/KBEI.2017.8324992.

[41] M.Y. Naing, A.S. Oo, I. Nilkhamhang, and T. Than, "Development of computer vision-based movement controlling in mecanum wheel robotic car", The 1st International Symposium on Instrumentation, Control, Artificial Intelligence, and Robotics (ICA-SYMP), Bangkok, Thailand, pp. 4548, 2019. https://doi.org/10.1109/ICASYMP.2019.8646254. 